\title{
Turbulent fluxes above the snow surface
}

\author{
Eric Martin, Yves Lejeune \\ Centre d'Études de la Neige, Centre National de Recherches Météorologiques, Météo-France, 38406 Saint-Martin-d'Héres Cedex, France
}

\begin{abstract}
Measurements of sensible- and latent-heat fluxes under stable conditions are rare. In order to obtain indirect measurements of turbulent fluxes, meteorological data measured at the Col de Porte laboratory ( $1320 \mathrm{~m}$ a.s.l, France) under very stable conditions (cold, clear night with low wind) are used. The radiative fluxes are measured, the conduction within the snowpack is calculated using the snow model Crocus and the turbulent fluxes are determined as a residual term of the surface-energy balance equation. These data were used to fit a new parameterization of the turbulent fluxes for the snow model. The turbulent fluxes are increased as compared to the theory. Crocus was also applied to the data from the LEADEX92 experiment and the turbulent fluxes calculated by the model were compared to the fluxes measured using sonic anemometers/thermometers on the site.
\end{abstract}

\section{INTRODUCTION}

An accurate estimate of the surface fluxes is crucial for snow modelling. The presence of snow on the ground is usually associated with a stable atmospheric boundary layer, because of the radiative properties of snow. However, measurements of the sensible- and latent-heat fluxes in stable stratification are very rare. Flux and profile measurements have been made recently in Antarctica (King, 1990; King and Anderson, 1994; Bintanja and van den Broeke, 1995). They found that the estimates of surface turbulent fluxes are rather uncertain in the case of high stability and low wind-speed conditions. King and Anderson (1994) also concluded that the fluxes are very sensitive to the orography, and the scalar roughness length has to be increased in the case of complex topography. Plüss and Mazzoni (1994) calculated turbulent fluxes over a melting snow pack in a high Alpine site (Weissflujoch, Davos, $2540 \mathrm{~m}$ ) with a roughness length equal to $1 \mathrm{~mm}$. As shown by Brun and others (1989), turbulent fluxes are an important term in the surfaceenergy balance in temperate mountain conditions. They can become critical during clear nights when they balance the nocturnal radiative cooling. Small errors in these fluxes induce large errors in the modelled surface temperature.

The parameterization of sensible- and latent-heat fluxes in a snow model is usually based on meteorological data at a given layer in the atmosphere and at the snow surface. Empirical exchange coefficients are often used. The purpose of this paper is to use results from two test sites to improve the parameterization of the turbulent fluxes for snow models. The first experiment was conducted at the Col de Porte laboratory (situated in the French Alps at $1320 \mathrm{~m}$ a.s.l). Hourly measurements of meteorological and snow variables are available and the use of the snow model Crocus (Brun and others, 1989, 1992) allows determination of the turbulent fluxes as a residual term of the surface-energy balance. In a second step, Crocus is also run on data from the LEADEX92 experiment (Ruffieux and others, 1994) from which measurements of turbulent fluxes are available.

\section{FORMULATION OF TURBULENT FLUXES}

According to Deardorff (1968) and Brun and others (1989), the parameterization of the sensible-heat flux $Q h$ and the latent-heat flux $Q e$ can be expressed as :

$$
\begin{aligned}
Q h & =\rho_{\mathrm{a}} C p_{\mathrm{a}} C_{\mathrm{h}} U(T a-T s) \\
Q e & =\frac{L s \rho_{\mathrm{a}}}{P_{\mathrm{a}}} \frac{M_{v}}{M_{\mathrm{a}}} C_{\mathrm{e}} U\left(e_{\mathrm{i}}(T a) H-e_{\mathrm{i}}(T s)\right)
\end{aligned}
$$

where $\rho_{\mathrm{a}}$ is air density, $C p_{\mathrm{a}}$ is the specific heat of air, $U$ is wind speed, $T a$ is air temperature, $L s$ is latent heat of ice sublimation, $P_{\mathrm{a}}$ is the atmospheric pressure, $M_{v} / M_{\mathrm{a}}$ is the ratio between water-vapour and dry-air molecular weights, $e_{\mathrm{i}}$ is the saturation vapour pressure above a flat ice surface at a temperature $T, H$ is the relative air humidity and $T s$ is the snow surface temperature. $C_{\mathrm{h}}$ and $C_{\mathrm{e}}$ are the adimensional coefficients depending on the surface roughness $\left(Z_{0}\right)$ and the air stability. In the following, $C_{\mathrm{h}}$ and $C_{\mathrm{e}}$ will be assumed equal and noted $C$. The formulation of $C$ proposed by Deardorff (1968) and Webb (1970) is used. The atmosphere stability is defined by the bulk Richardson number Ri :

$$
\mathrm{Ri}=\frac{2 g}{T a} \times \frac{T a-T s}{Z_{0}} \times \frac{Z_{\mathrm{U}}}{U}
$$

where $Z_{\mathrm{U}}$ and $Z_{\mathrm{a}}$ are the heights of the wind and temperature measurements. In the neutral case $(\mathrm{Ri}=0)$ :

$$
C_{\mathrm{n}}=\frac{k^{2}}{\ln \left(\frac{Z_{\mathrm{u}}}{Z_{0}}\right) \times \ln \left(\frac{Z_{\mathrm{u}}}{Z_{0}}\right)}
$$

where $k$ is the von Kármán constant. In the stable case $(\mathrm{Ri}>0)$,

$$
C=C_{\mathrm{n}} \times(1-5 \mathrm{Ri})^{2}
$$


In the unstable case $(\mathrm{Ri}<0)$,

$$
C=C_{\mathrm{n}} \times\left(1+\frac{7}{a} \ln (1-a \mathrm{Ri}) \quad \text { with } a=0.83 C_{\mathrm{n}}^{-0.62}\right. \text {. }
$$

\section{ASSESSMENT OF TURBULENT FLUXES FROM GOL DE PORTE DATA}

Col de Porte is a typical middle-altitude site (1320 a.s.l) situated in the vicinity of a pass. Although the site can be considered more or less flat (slope $<5^{\circ}$ ), the influence of the surrounding mountains is important. The purpose of this section is to use the meteorological and snow records, as well as the snow model Crocus to derive the turbulent fluxes as a residual term of the surface-energy balance. In a second step, the fluxes will be compared with the classical parameterizations described in the previous section. Nights with low wind and clear sky were chosen because of the strong air stability. Hence, the formulation of turbulent fluxes is critical during these periods. In the absence of solar radiation, precipitation and snowmelt near the snow surface, the surface-energy budget can be expressed as follows: $Q l \downarrow+Q l \uparrow+Q h+Q e+Q$ cond $=0$ where $Q l \downarrow$ is the incoming longwave radiation, $Q l \uparrow$ is the outgoing longwave radiation, $Q$ cond is the conduction flux in the snow at the surface. $Q l \downarrow$ is measured, $Q l \uparrow$ and $Q$ cond are calculated using the snow model; the remaining terms $Q h+Q e$ can be deduced from the surface-energy equation.

We used the data collected hourly at this site. $Q l \downarrow$ and $Q l \uparrow$ are measured by pyrgeometers, other meteorological data used for the actual determination of the exchange coefficient (air temperature, humidity and wind speed) are measured concurrently hourly. The snow model is initialized with a snow pit made during the afternoon. If no snow profile is available, we use results from a previous simulation, corrected if necessary using automatic temperature records within the snowpack. Crocus is run on an hourly time-step using measured input data and prescribed values of $Q h+Q e$. An iterative process is used and $Q h+Q e$ is changed until the calculated surface temperature (or $Q l \uparrow$ ) matches the observed one. This determination was conducted on data from the winter of 1988-89. Some problems were encountered in the determination of an initial snow profile when no snow pits and no snow temperature near the surface were available. Other problems came from hoar deposition on pyrgeometers. In these cases, the results were strongly affected and from the 12 clear, calm nights that were selected only eight nights were retained ( 53 hours).

The values of $Q h+Q e$ are all positive (heat is transferred from the atmosphere to the snow) and they vary between 9 and $60 \mathrm{~W} \mathrm{~m}^{-2}$, whilst the mean wind speed varies between 0.1 and $2.7 \mathrm{~m} \mathrm{~s}^{-1}$. The coefficient $C=C_{\mathrm{h}}=C_{\mathrm{e}}$ is derived from Equations (1) and (2):

$$
C=\frac{Q_{t}}{\rho_{\mathrm{a}} C p_{\mathrm{a}} U(T a-T s)+\frac{L s \rho_{\mathrm{a}}}{P_{\mathrm{a}}} \frac{M_{v}}{M_{\mathrm{a}}} U\left(e_{\mathrm{i}}(T a) H-e_{\mathrm{i}}(T s)\right)} .
$$

$Q_{t}=Q h+Q e$ is the total turbulent transfer between air and snow. $C$ is plotted as a function of the hourly mean of wind velocity in Figure 1. The high values of $C$ for a very low wind speed are probably due to measurement problems (inertia and the starting threshold of the anemometer). In this range of wind speed, the estimated turbulent fluxes are small $\left(10-20 \mathrm{~W} \mathrm{~m}^{-2}\right)$ and the experimental determination of $C$ is also very sensitive to errors in the measured longwave radiation (assumed generally to be $\pm 10 \mathrm{~W} \mathrm{~m}^{-2}$ ). For a wind speed between 0.3 and $1.0 \mathrm{~m} \mathrm{~s}^{-1}, C$ is extremely variable, but for wind speed higher than $1.0 \mathrm{~m} \mathrm{~s}^{-1} C$ is almost constant (mean value: 0.0034 ).

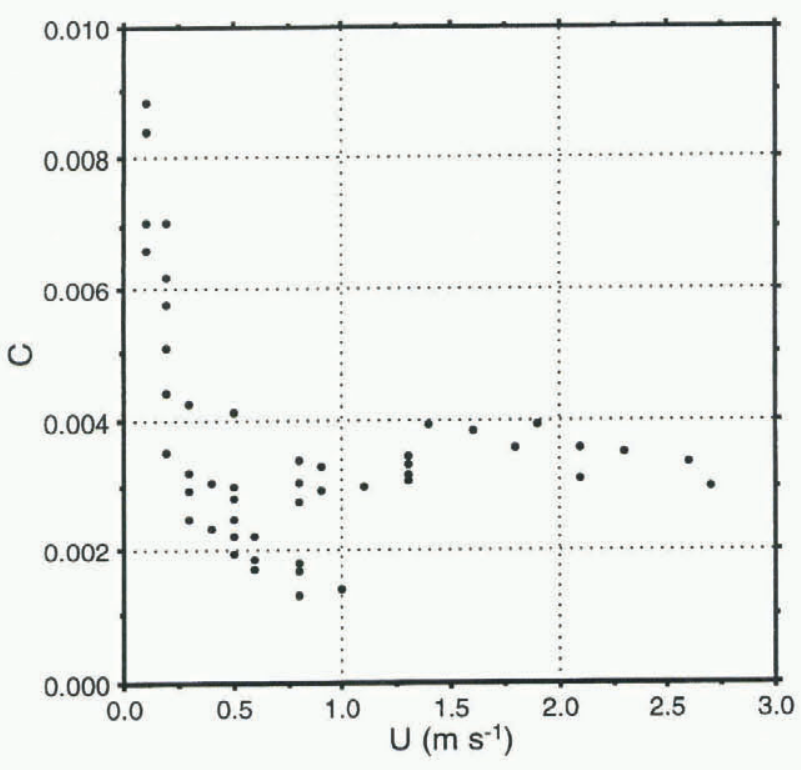

Fig. 1. Dependence of the empirical exchange coefficient $C$ on the hourly mean of wind speed.

In all these experiments, the hourly Richardson number $\mathrm{Ri}$ is greater than 0.2 . Under these conditions, the turbulent fluxes are supposed to be equal to 0 (see Equation (4)). As found by previous studies (Halberstam and Schieldge, 1979; Schieldge and Halberstam, 1979) with data recording at a shorter time-step, periods of negligible turbulent-heat flux alternate with moderately stable conditions with a higher heat flux. The mean flux (as determined experimentally here) is the result of periodic turbulent bursts. This is why classical anemometers are inadequate for the assessment of mean fluxes, in the case of very stable conditions with low wind. Nevertheless, for a mean wind speed above $1 \mathrm{~m} \mathrm{~s}^{-1}$, the turbulent fluxes can be parameterized by a constant exchange coefficient with relatively good accuracy. The experimental value of $C$ for strong stability is of the same order as $C_{\mathrm{n}}$ for $Z_{0}=0.002 \mathrm{~m}\left(0.0032\right.$ with $Z_{\mathrm{U}}=2.50 \mathrm{~m}$ and $\left.Z_{\mathrm{a}}=2 \mathrm{~m}\right)$. This value of $Z_{0}$ is higher than the values given by studies on a flat area, as discussed by Morris (1989) and Plüss and Mazzoni (1994). This definitely proves that the classical formulation of the turbulent fluxes is inadequate for snow modelling in mountainous and stable conditions, especially if conventional data (hourly temperature and wind speed at a single level) are used as input data. After several tests, we propose using a modified formulation for $C$ in the stable case:

$$
C=\rho_{\mathrm{a}} C_{\mathrm{pa}} C_{\mathrm{n}} \max \left(\alpha,(1-5 \mathrm{Ri})^{2}\right)
$$

with the assumption of $\alpha=0.75$. This formulation allows a decrease of $C$ when stability increases $(0<\mathrm{Ri}<0.026)$ and the existence of turbulent exchanges even with strong stability. In order to maintain reasonable turbulent exchanges, 
even in the case of low winds, a minimum of $0.3 \mathrm{~m} \mathrm{~s}^{-1}$ is imposed for $U$. Figure 2 compares the exchange coefficient $C$ derived from Equations (3), (4), (6) and (8) for different $Z_{0}$ values to the experimental value deduced from Figure 1.

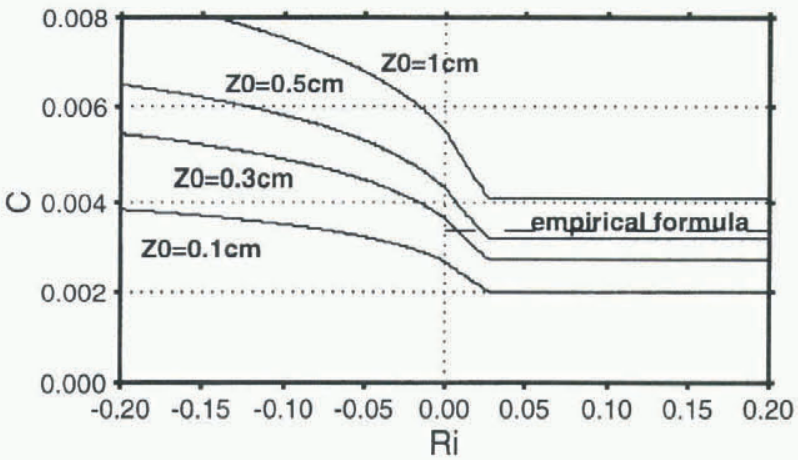

Fig. 2. Comparison between the empirical coefficient $C$ and the exchange coefficients derived from theory for various $Z_{0}$.

\section{TESTS ON COL DE PORTE DATA}

The new parameterization was tested on the simulation of the snow cover during the winter of 1993-94. This winter was characterized by three cold periods (end of December, mid-January and mid-February), when the minimum air temperature was lower than $-10^{\circ} \mathrm{C}$. Continuous snow cover remained from 15 November 1993 to 5 May 1994. The Crocus model was run using the observed hourly meteorological data (air temperature, humidity, wind speed, incoming solar and longwave radiation and precipitation) without any reinitialization. The initial conditions are no snow on 11 November 1993. Table 1 summarizes the performance of the model in reproducing the snow-surface temperature for various parameterizations of the turbulent fluxes. As it is intended to focus on very stable conditions, when turbulent fluxes are crucial, only periods when the measured surface temperature is lower than $-5^{\circ} \mathrm{C}$ are considered ( 1100 hours). For low $Z_{0}$, the turbulent fluxes are underestimated and the surface temperature is too low. On the contrary, they are overestimated for high values of $z_{0}(10 \mathrm{~mm})$. The best results are obtained when $Z_{0}=5$ or $7 \mathrm{~mm}$ (they are very similar to those obtained using the empirical $C$ deduced from measurements). These tests are encouraging, because the calibra-

Table 1. Col de Porte data. Performance of the snow model Crocus for the simulation of surface temperature, using the empirical exchange coefficient and various $Z_{0}$ (results for measured temperature $<-5^{\circ} \mathrm{C}$ )

\begin{tabular}{|c|c|c|c|c|}
\hline & $\bar{T}_{\mathrm{s}}$ & $\bar{T}_{\mathrm{s}}$ & Mean error & $r m s$ \\
\hline & $\begin{array}{c}\text { Measured } \\
{ }^{\circ} \mathrm{C}\end{array}$ & $\begin{array}{c}\text { Simulated } \\
{ }_{\mathrm{C}}^{\circ}\end{array}$ & ${ }^{\circ} \mathrm{C}$ & ${ }^{\circ} \mathrm{C}$ \\
\hline Empirical value $(\alpha=0.75)$ & -9.499 & -9.498 & +0.001 & 1.365 \\
\hline$Z_{0}=1 \mathrm{~mm}(\alpha=0.75)$ & -9.499 & -9.913 & -0.414 & 1.552 \\
\hline$Z_{0}=3 \mathrm{~mm}(\alpha=0.75)$ & -9.499 & 9.689 & -0.190 & 1.416 \\
\hline$Z_{0}=5 \mathrm{~mm}(\alpha=0.75)$ & -9.499 & -9.521 & -0.022 & 1.368 \\
\hline$Z_{0}=7 \mathrm{~mm}(\alpha=0.75)$ & -9.499 & -9.420 & +0.079 & 1.351 \\
\hline$Z_{0}=10 \mathrm{~mm}(\alpha=0.75)$ & -9.499 & -9.275 & +0.224 & 1.376 \\
\hline$Z_{0}=5 \mathrm{~mm}(\alpha=0)$ & -9.499 & -10.490 & -0.987 & 2.043 \\
\hline
\end{tabular}

tion based on few data gives good results when applied to independent data from the same site. The snow-depth simulation using $Z_{0}=5 \mathrm{~mm}$ (Fig. 3 ) is in very good agreement with the observations. The frequency of stable stratification is $95 \%$. The apparent underestimation of snowmelt in the simulation (especially at the end of March and beginning of May) is due to enhanced melting near the snow-depth sensor, because of the nearness of various sensors of the site. The limitation of $C$ plays a major role in the surface-temperature simulation. The run with $Z_{0}=5 \mathrm{~mm}, \alpha=0$ and no wind threshold shows a significant decrease in the simulated surface temperature. This decrease is marked for a very low temperature: errors of $-5^{\circ} \mathrm{C}$ are common for measured temperatures below $-15^{\circ} \mathrm{C}$.

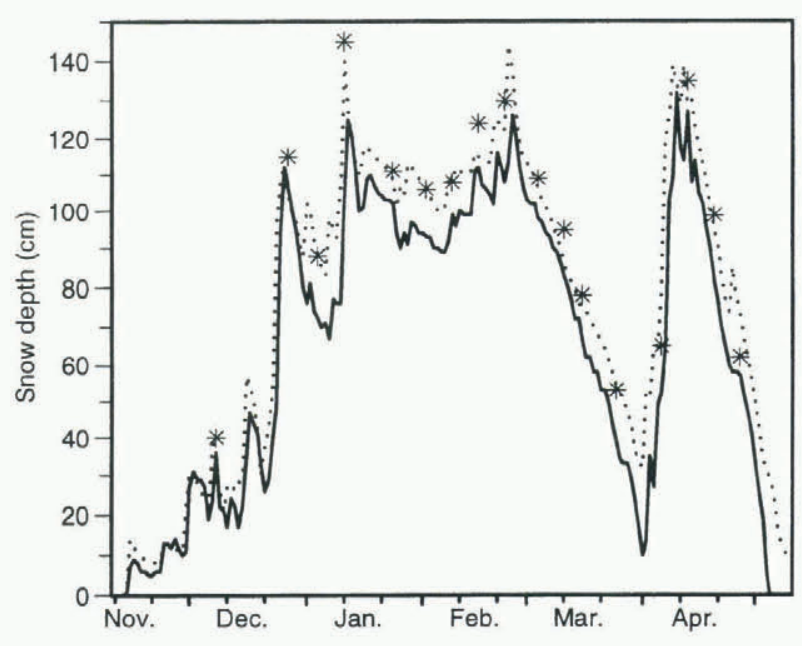

Fig. 3. Comparison between observed (continuous line) and simulated (dashed line) snow depth at Col de Porte (winter 1993-94). *, snow depth from pit observation (20 m away from the automatic snow-depth sensor).

\section{TESTS ON LEADEX92 DATA}

The LEADEX92 experiment (Ruffieux and others, 1994) was conducted in the Beaufort Sea in March and April 1992. The centre of the field experiment was the base camp on the permanent ice pack about $270 \mathrm{~km}$ north of the coast of Alaska. Meteorological variables were recorded at this site between 23 March and 21 April 1992. They also included sonic anemometers/thermometers which were used to provide direct measurements of the sensible-heat flux. The air temperature varies from $-31^{\circ}$ to $-8^{\circ} \mathrm{C}$. The mean wind speed is $4.3 \mathrm{~m} \mathrm{~s}^{-1}$. The snow-surface temperature varies between $-35^{\circ}$ and $-9^{\circ} \mathrm{C}$, its diurnal amplitude is in the order of $10^{\circ} \mathrm{C}$, usually higher than that for the air temperature. The frequency of stable stratification is $40 \%$, instead of $95 \%$ in the case of Col de Porte. Because some surface temperatures were suspicious, all comparisons and tests were made on the last 600 hours of the period.

One of the main problems encountered in using these data is determination of the initial snow conditions, because no detailed snow and ice profiles were available. At the base camp, the ice thickness was about $3 \mathrm{~m}$ and the ice was covered by snow.

\section{Initial snow profile}

Because of the relatively short simulation period (28 days), initial conditions played a significant role. The initial sur- 
Table 2. LEADEX92 data. Performance of the snow model Crocus for the simulation of surface temperature using various estimated initial ice and snow profiles (i.e. snow heights) and $Z_{0}$

\begin{tabular}{|c|c|c|c|c|c|c|c|}
\hline $\begin{array}{l}\text { Snow height }(\mathrm{mm}) \\
\text { Surface roughness (mm) }\end{array}$ & $Z_{0}^{20}=5$ & $\begin{array}{c}400 \\
Z_{0}=5\end{array}$ & $\begin{array}{c}800 \\
Z_{0}=5\end{array}$ & $\begin{array}{c}400 \\
Z_{0}=1\end{array}$ & $\begin{array}{c}400 \\
Z_{0}=3\end{array}$ & $\begin{array}{c}400 \\
Z_{0}=7\end{array}$ & $Z_{0}^{400}=10$ \\
\hline Error $\min (\mathbf{K})$ & -3.81 & -3.46 & -3.21 & -3.15 & -3.36 & -3.54 & -3.56 \\
\hline Error $\max (\mathbf{K})$ & 4.59 & 2.66 & 2.42 & 2.97 & 2.84 & 2.77 & 2.75 \\
\hline Mean error $(\mathbf{K})$ & 0.06 & -0.66 & -0.89 & -0.72 & -0.65 & -0.59 & -0.55 \\
\hline $\operatorname{rms}(\mathrm{K})$ & 2.02 & 1.22 & 1.25 & 1.23 & 1.19 & 1.24 & 1.28 \\
\hline
\end{tabular}

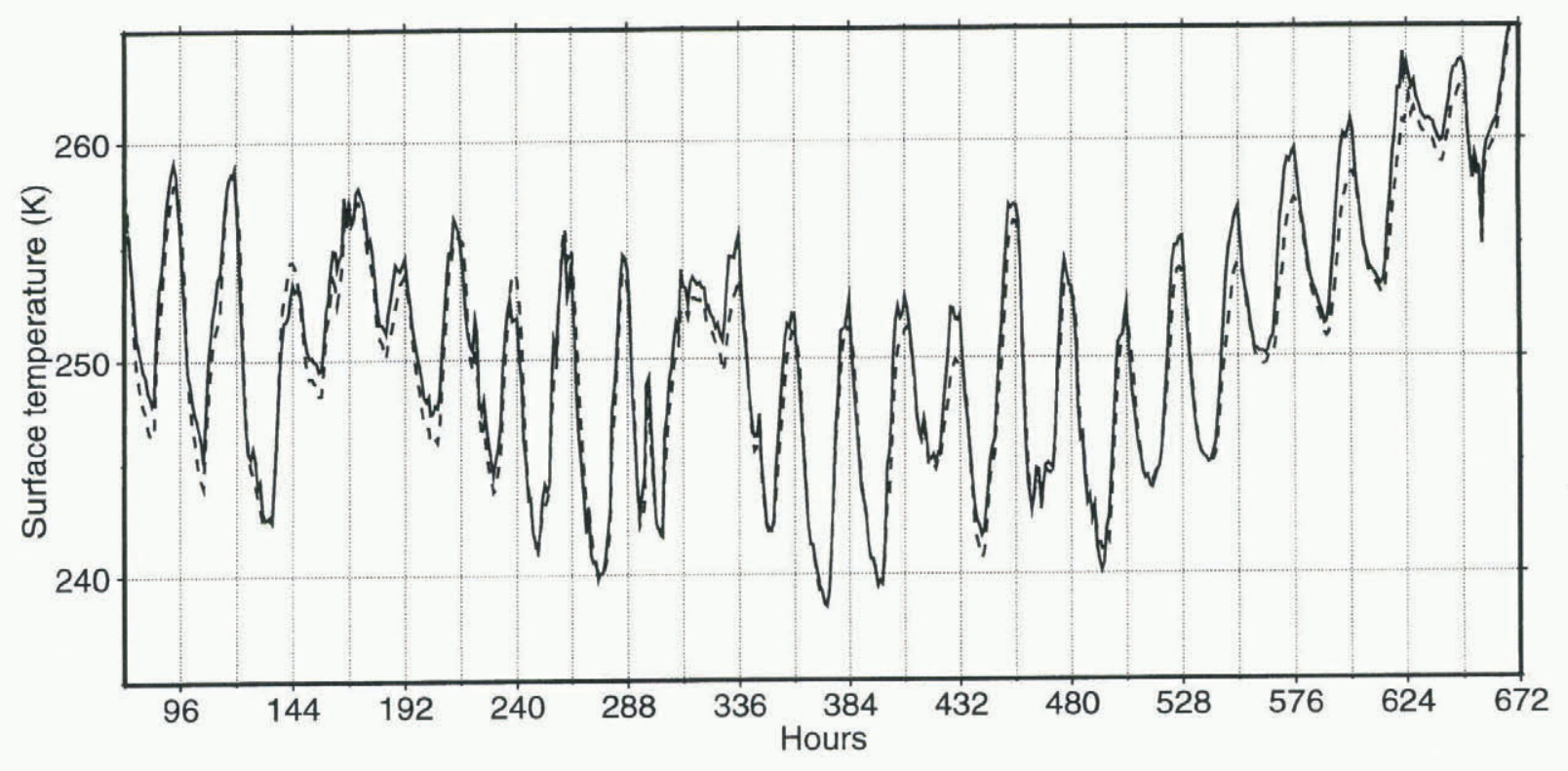

Fig. 4. Comparison between observed (continuous line) and simulated (dashed line) snow-surface temperature for the LEADEX92 test site.

face temperature was set to the observed one $\left(-24^{\circ} \mathrm{C}\right)$ and the bottom temperature of the ice pack was set to $-1.8^{\circ} \mathrm{C}$. The ice thickness was set to $3 \mathrm{~m}$ and several snow heights above the ice were tested (snow density was fixed at $300 \mathrm{~kg} \mathrm{~m}^{-3}$ ). At this stage, the roughness length was still set to $5 \mathrm{~mm}$. Table 2 summarizes the ability of the model to simulate the surface temperature using various initial snow profiles. For shallow snowpacks $(20 \mathrm{~mm})$, the global thermal inertia and heat capacity is very high, the diurnal cycle of the surface temperature is underestimated ( $\mathrm{rms}$ error $2.02^{\circ} \mathrm{C}$ ). If the snow height is equal to $0.40 \mathrm{~m}$, the simulated temperature is much more in agreement with observation ( $r$ s error $1.22^{\circ} \mathrm{C}$ ), even if a cold bias appears in the results. For higher snowpacks $(0.80 \mathrm{~m})$, the results are slightly degraded ( $r m s$ error of $1.25^{\circ} \mathrm{C}$ ), the mean error is also degraded. The best results are obtained with $0.40 \mathrm{~m}$ of snow and this height will be retained in the following.

\section{Turbulent fluxes}

All tests in the previous section were made using a surface roughness of $5 \mathrm{~mm}$. In the Col de Porte case, the relatively high $Z_{0}$ was justified by the orography, which was supposed to induce mechanical turbulence even in the case of very stable stratification. In the LEADEX92 experiment, several $Z_{0}$ values, varying from 1 to $10 \mathrm{~mm}$ were tested and the results for the surface temperature are shown in Table 2. Probably, because of the relatively high wind speed, the simulation is not very sensitive to the formulation of the exhttps://doi.org/10.3189/1998AoG26-1-179-183 Published online by Cambridge University Press change coefficient. For a low $Z_{0}$, the simulated temperature decreases (see the mean error in Table 2). The rms error for the surface temperature is at a minimum for $Z_{0}=3 \mathrm{~mm}$. This value is lower than the $Z_{0}$ adjusted for the Col de Porte data and confirms the hypothesis of turbulence induced by

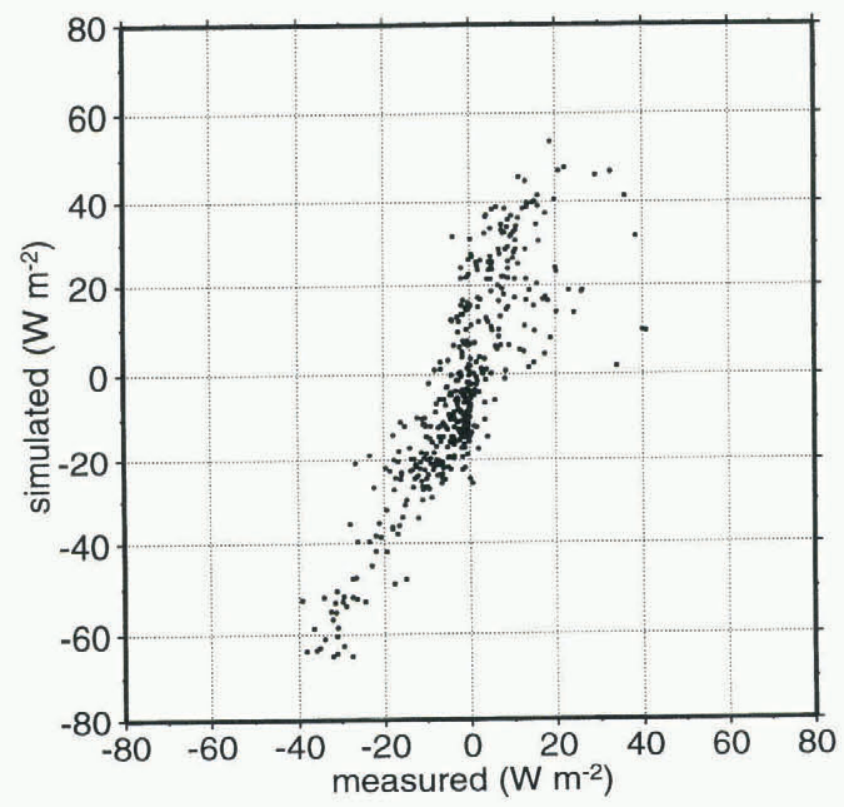

Fig. 5. Comparison between measured and simulated sensibleheat flux for the LEADEX92 test site (positive fluxes are associated with stable stratification). 
orography in the mountains. The simulated surface temperature (Fig. 4) is in very good agreement with the observations. Figure 5 shows a comparison of the turbulent-heat flux with measurements by sonic anemometers and thermistors. Most of the characteristics (flux direction associated with stable/unstable stratification and diurnal cycle) are well reproduced, but the fluxes are too high in the model. As already mentioned, this problem does not come from the $Z_{0}$ prescribed in Crocus because the results are not strongly sensitive to this parameter: if $Z_{0}$ is increased, the exchange coefficient is increased but the difference between air temperature and surface temperature is also decreased and the fluxes are not very much affected. Other problems may derive from uncertainties in the initial snow and ice profile, the boundary condition or even measurements of the parameters used to drive the model. Because of the short simulation period, the results are too sensitive to the initial profile to be conclusive on this point.

\section{CONCLUSION}

The difficulties of parameterization of turbulent fluxes in the snow models derive from the fact that usually few measurements are available (air temperature, humidity and wind speed at one level only) and that stable stratifications, which are not well documented, are common at least during night times. The experiment made at Col de Porte (a mountainous site) showed that the formulae derived from theory have to be modified in snow models. Limitation of the Richardson number for a stable case in the Deardorff (1968) formulae improved the results. The same parameterization (with decreased $Z_{0}$ ) applied to the LEADEX92 data yielded very good results for the surface temperature. However, the problem of simulation of the turbulent-heat flux could not be resolved. At the Col de Porte site, mechanical or orographic induced turbulence produces exchange rates higher than in theory. This is probably the case in all mountainous sites. During the LEADEX92 experiment, with a high wind speed, the results are not too dependent on the formulation of the turbulent fluxes. The question of the parameterization of turbulent fluxes in atmospheric modelling has already been addressed by several authors (e.g. Beljaars and Holstag, 1991). Usually, an effective roughness length is used. It is generally larger than the local value and accounts for heterogeneity in an upwind stream. The two experiments described here confirm that parameter- ization of turbulance is highly dependent on the site (especially in stable conditions), and that no universal or simple formula can be determined.

\section{ACKNOWLEDGEMENTS}

We wish to thank P. O. Persson (CIRES, University of Colorado), who provided us with the LEADEX92 data. This research was supported by the EC Environment and Climate Research Programme (contract ENV4-CT950076, Climatology and Natural Hazards).

\section{REFERENGES}

Beljaars, A. and A. Holtslag. 1991. Flux parameterization over land surface for atmospheric models. 7. Appl. Meteorol., 30,327-341.

Bintanja, R. and M. R. van den Broeke. 1995. Momentum and scalar transfer coefficients over aerodynamically smooth Antarctic surfaces. Boundary-Layer Meteorol., 74(1-2), 89-111.

Brun, E., E. Martin, V. Simon, C. Gendre and C. Coléou. 1989. An energy and mass model of snow cover suitable for operational avalanche forecasting. 7. Glaciol., 35 (121), 333-342.

Brun, E., P. David, M. Sudul and G. Brunot. 1992. A numerical model to simulate snow-cover stratigraphy for operational avalanche forecasting. 7. Glaciol., 38 (128), 13-22.

Deardorff, J.W. 1968. Dependence of air-sea transfer coefficients on bulk stability. 7. Geophys. Res., 73 (8), 2549- 2557.

Halberstam, I. M. and P. Schieldge. 1979. Interaction between the atmospheric boundary layer and a snow surface. Part I. Modelling. In Colbeck, S. C. and M. Ray, eds. Modeling of Snow Cover Runoff, 26-28 September 1978, Hanover, New Hampshire. Proceedings. Hanover, NH, U.S. Army Corps of Engineers. Cold Regions Research and Engineering Laboratory, $154-160$.

King, J. C. 1990. Some measurements of turbulence over an Antarctic ice shelf. Q. 7. R. Meteorol. Soc., 116, 379-400.

King, J. C. and P. S. Anderson. 1994. Heat and water vapour fluxes and scalar roughness lengths over an Antarctic ice shelf. Boundary-Layer Meteorol., $69(1-2), 101-121$.

Morris, E. M. 1989. Turbulent transfer over snow and ice. 7. Hydrol., 105, 205-223.

Plüss, Ch. and R. Mazzoni. 1994. The role of turbulent heat fluxes in the energy balance of high Alpine snow cover. Nord. Hydrol., 25 (1-2), 25-38.

Ruffieux, D., P. O. G. Persson, C.W. Fairall and D. E. Wolfe. 1995. Ice pack and lead surface energy budgets during LEADEX 1992. 7. Geophys. Res., 100 (C3), 4593-4612.

Schieldge, P. and I. M. Halberstam. 1979. Interaction between the atmospheric boundary layer and a snow surface. Part II. Measurements. In Colbeck, S. C. and M. Ray, eds. Modeling of Snow Cover Runoff, $26-28$ September 1978, Hanover, New Hampshire. Proceedings. Hanover, NH, U.S. Army Corps of Engineers. Cold Regions Research and Engineering Laboratory, 161-166.

Webb, E. K. 1970. Profile relationships: the log-linear range, and extensions to strong stability. Q. J.R. Meteorol. Soc., 96, 67-90. 